\title{
Strategi Pengisian Baterai pada Sistem Panel Surya Standalone Berbasis Kontrol PI Multi-Loop
}

\author{
Khusnul Hidayat*, Mohammad Chasrun Hasani, Nur Alif Mardiyah, dan Machmud Effendy \\ Program Studi Teknik Elektro, Fakultas Teknik, Universitas Muhammadiyah Malang \\ Jl. Raya Tlogomas No.246 Malang, Jawa Timur, 65144, Indonesia \\ *Corresponding author. Email: khusnulhidayat@umm.ac.id
}

\begin{abstract}
This study discusses the power control strategy in a standalone photovoltaic-battery hybrid system. The life-time of the battery will be shorter if the battery is often charged with high current and exceeds its State-of-Charge (SoC). Therefore, a control method is needed to control the power flow on the DC bus and the charging current as well as the SoC of the battery so that the battery has a long life-time. The proposed system uses two dc-dc converters to connect photovoltaic (PV) and lead-acid batteries to the load. The unidirectional DC-DC converter is used as the interface between the PV and the DC bus, the bidirectional $D C-D C$ converter is used as the interface between the battery and the DC bus. The control strategy plays a role in controlling the power flow between the converter and the load to maintain the balance of power in the system and controlling the battery to support PV when the available PV power is not enough to meet the load. The multi-loop control strategy is proposed in this study, one of the loops is used to maintain the SoC of the battery in order to control the PV output power to avoid over-charging. Another loop is used to ensure the balance of the system's power when the battery is charging at its maximum charge current. The proposed control system is implemented without requiring any conditions for the control to operate. The simulation results show that the proposed multi-loop control can control the power flow in the system while maintaining the maximum charging current and battery SoC limits.
\end{abstract}

Keywords-MPPT, photovoltaic, battery, state of charge, DC-DC Converter, standalone, bidirectional, multi-loop control

Abstrak- Penelitian ini membahas strategi kontrol daya pada sistem hibrid photovoltaic-baterai yang berdiri sendiri (standalone). Masa pakai (life-time) baterai akan semakin pendek jika baterai sering diisi dengan arus tinggi dan melebihi kapasitasnya (State-of-Charge (SoC)). Oleh karena itu, diperlukan metode kontrol untuk mengendalikan aliran daya pada bus DC, arus pengisian, dan SoC baterai agar baterai memiliki life-time yang panjang. Sistem yang diusulkan menggunakan dua buah konverter dc-dc untuk menghubungkan photovoltaic (PV) dan baterai lead-acid ke beban. Konverter DC-DC searah (unidirectional) digunakan sebagai antarmuka antara PV dan bus DC, sedangkan konverter DC-DC dua arah (bidirectional) digunakan sebagai antarmuka antara baterai dan bus DC. Strategi kontrol berperan mengendalikan aliran daya antara konverter dan beban untuk menjaga keseimbangan daya dalam sistem dan mengendalikan baterai untuk mendukung PV ketika daya PV yang tersedia tidak cukup untuk memenuhi beban. Strategi kontrol multi-loop digunakan pada penelitian ini, salah satu loop digunakan untuk menjaga SoC baterai dalam rangka mengendalikan daya keluaran PV untuk menghindari pengisian berlebihan (over-charging). Loop yang lain digunakan untuk memastikan keseimbangan daya sistem saat baterai sedang diisi pada batas maksimal arus pengisiannya. Sistem kontrol yang diusulkan, diimplementasikan tanpa memerlukan syarat kondisi apapun agar kontrol tersebut dapat beroperasi. Hasil simulasi menunjukkan bahwa kontrol multi-loop yang diusulkan dapat mengendalikan aliran daya pada sistem dengan tetap menjaga batas maksimal arus pengisian dan SoC baterai.

Kata kunci- MPPT, panel surya, baterai, state of charge, konverter DC-DC, standalone, bidirectional, kontrol multi-loop

\section{PENDAHULUAN}

Photovoltaic (PV) atau dikenal dengan panel surya memiliki beberapa kelebihan di antaranya adalah emisi yang rendah dan perawatan yang sangat mudah. Akan tetapi, panel surya juga memiliki kekurangan atau kelemahan yaitu harganya yang masih mahal dan energi matahari yang tidak stabil serta hanya bisa dipanen saat siang hari saja. Kebutuhan akan energi baru dan terbarukan saat ini semakin besar mendorong jumlah produksi PV yang tinggi dan peningkatan teknologi yang semakin canggih sehingga berdampak pada penurunan biaya produksi. Masalah panel surya yang tidak mampu menghasilkan energi listrik secara terus menerus (kontinu) dapat diatasi dengan cara mengombinasikan dengan pembangkit listrik tenaga bayu atau gas, namun cara yang paling mudah adalah dengan mengombinasikan dengan sistem penyimpanan (baterai), sehingga terciptanya sistem hibrid photovolatic-baterai yang dapat menyeimbangkan pembangkit PV dengan beban [1] - [4].

Baterai Lead Acid sering digunakan pada sistem panel surya karena bebas perawatan, relatif murah, mampu discharging hingga $80 \%$ dari kapasitasnya (deep discharging), dan memiliki tingkat bahaya yang sedikit dibandingkan dengan jenis lainnya. Akan tetapi, baterai Lead Acid juga memiliki kelemahan yaitu masa pakai (life-time) yang pendek dibandingkan dengan baterai Lithium-Ion. Life-time baterai 
akan semakin pendek jika baterai sering diisi dengan arus tinggi dan melebihi kapasitasnya. Oleh karena itu, diperlukan metode kontrol untuk menjaga aliran daya pada bus DC dan arus pengisian serta State-of-Charge (SoC) baterai agar baterai memiliki life-time yang panjang [4] - [7].

Terdapat penelitian terdahulu yang sudah mencoba mengembangkan strategi kontrol pada sistem hibrid PV-baterai. Diantaranya, kontrol adaptif berbasis Passivity dengan identifikasi parameter aljabar [1]. Metode tersebut dikembangkan untuk menjaga tegangan bus DC dengan mengendalikan dua buah konverter DC-DC. Akan tetapi, pada penelitian tersebut tidak membahas kontrol pengisian dan SoC baterai. Beberapa penelitian [3], [8] - [10], mengusulkan strategi kontrol sistem hibrid PV-baterai berbasis kondisi diskrit, suatu kontrol hanya akan berjalan jika sebuah kondisi yang sudah ditentukan terpenuhi. Referensi [11] - [13] mengusulkan kontrol SoC baterai tanpa memerlukan syarat kondisi diskrit, kontrol yang diusulkan beroperasi pada sistem hibrid PV-baterai. Strategi yang diusulkan dalam [3], [8], [9], [11] - [13] tidak mempertimbangkan batasan maksimal arus saat pengisian baterai, sedangkan arus pengisian baterai LeadAcid harus dijaga agar tidak melebihi batas maksimal, dalam rangka menjaga masa pakai baterai [4].

Referensi [4] mengusulkan strategi kontrol sistem hibrid PV-baterai dengan menjaga arus maksimal saat pengisian dan SoC baterai tanpa memerlukan syarat kondisi diskrit, akan tetapi dengan metode yang diusulkan menimbulkan deviasi tegangan pada jaringan bus DC sebesar 5\%. Referensi [14], [15] juga mengusulkan manajemen daya pada sistem hibrid PVbaterai dengan menggunakan tiga buah konverter. Akan tetapi, manajemen daya yang diusulkan [14], [15] membutuhkan kontrol loop yang sangat kompleks dan pada penelitian tersebut tidak mengendalikan arus maksimal saat pengisian baterai dan tanpa mempertimbangkan batasan maksimal SoC baterai.

Oleh karena itu, penelitian ini mengusulkan strategi kontrol multi-loop pada sistem hibrid PV-baterai yang mencakup pembatasan arus charging dan kapasitas (SoC) baterai. Masingmasing kontrol konverter DC-DC menggunakan kontrol bertingkat dua loop berbasis kendali Proporsional dan Integral (PI). PI adalah sebuah kendali konvensional yang sederhana sehingga mudah diimplementasikan. Selain itu, pada sistem kendali dengan plant konverter, kendali PI memiliki efisiensi lebih baik dibandingkan dengan kendali Proporsional, Integral, dan Derivatif (PID) [16]. Strategi kontrol yang diusulkan dapat menjaga tegangan bus DC serta menjaga arus maksimal pengisian dan SoC baterai tanpa memerlukan syarat kondisi agar kontrol tersebut dapat beroperasi. Sistem PV sebesar 200 $\mathrm{W}_{\text {peak }}$ digunakan pada penelitian ini untuk menunjukkan kinerja sistem.

\section{MetodE}

Penelitian ini mengusulkan sistem hibrid PV-baterai dengan topologi dua konverter yang beroperasi secara independen, seperti yang ditunjukkan pada Gambar 1. Tegangan bus DC $v_{\text {bus }}$ dikendalikan oleh konverter DC-DC bidirectional, yang mana konverter tersebut terhubung ke baterai. Berdasarkan konfigurasi pemasangan konverter bidirectional, seperti yang ditunjukkan pada Gambar 1, tegangan nominal baterai harus lebih rendah dari pada tegangan bus DC. Konverter bidirectional dapat beroperasi pada dua mode, yaitu mode buck (step-down) saat tegangan bus $v_{\text {bus }}$ lebih tinggi dari pada tegangan bus referensi $v_{\text {busRef }}$ dan mode boost (step-up) saat tegangan bus $v_{\text {bus }}$ lebih rendah dari pada tegangan bus referensi vbusRef.

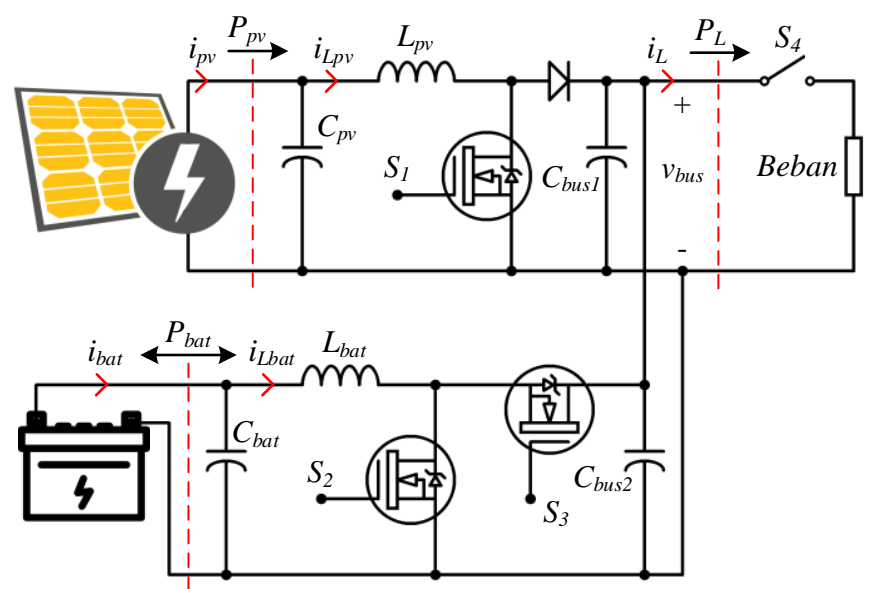

Gambar 1. Rangkaian sistem hibrid PV-baterai yang diusulkan

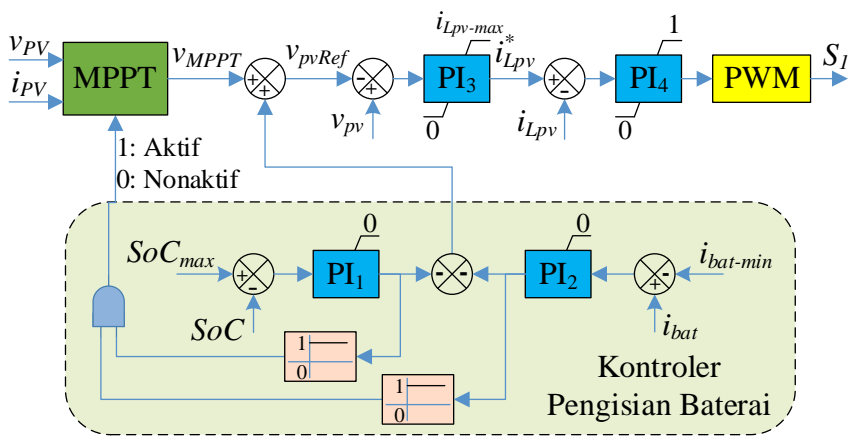

(a)

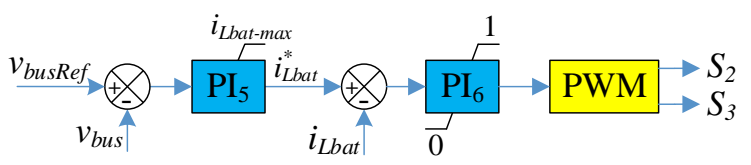

(b)

Gambar 2. Blok diagram sistem kontrol yang diusulkan: (a) kontrol konverter PV unidirectional dan (b) kontrol konverter baterai bidirectional

Desain kendali yang diusulkan pada penelitian ini ditunjukkan pada Gambar 2. Metode kontrol pada kedua konverter yang digunakan pada penelitian ini menggunakan kontrol bertingkat dua loop berbasis PI, seperti yang ditunjukkan pada Gambar 2. Kontroler $\mathrm{PI}_{4}$ dan $\mathrm{PI}_{6}$ berperan sebagai pengendali arus, sedangkan kontroler $\mathrm{PI}_{3}$ dan $\mathrm{PI}_{5}$ berperan sebagai pengendali tegangan. Berdasarkan kebutuhan daya beban dan daya PV yang dihasilkan, topologi yang diusulkan beroperasi dalam enam mode skenario.

Pelepasan beban tidak bisa dihindari ketika: 1) $\mathrm{SoC}$ baterai lebih rendah dari pada $S o C_{\min }, 2$ ) begitu juga saat daya keluaran PV dan maksimum daya konverter baterai tidak mencukupi kebutuhan beban. Skema kontrol histerisis diusulkan untuk mencegah kemungkinan tingginya frekuensi peralihan yang menyebabkan kerusakan pada kontaktor. Saklar $S_{4}$ akan terbuka (logika 0) saat $S o C$ baterai lebih rendah dari pada $S o C_{\min }$ sebesar $20 \%$, dan kembali tertutup (logika 1) jika $S o C$ baterai melebihi $S o C_{\text {mid }}$ sebesar $40 \%$ [9]. Skenario ini tidak ditunjukkan dalam sistem kontrol Gambar 2 karena dianggap sebagai bagian dari proteksi sistem. 


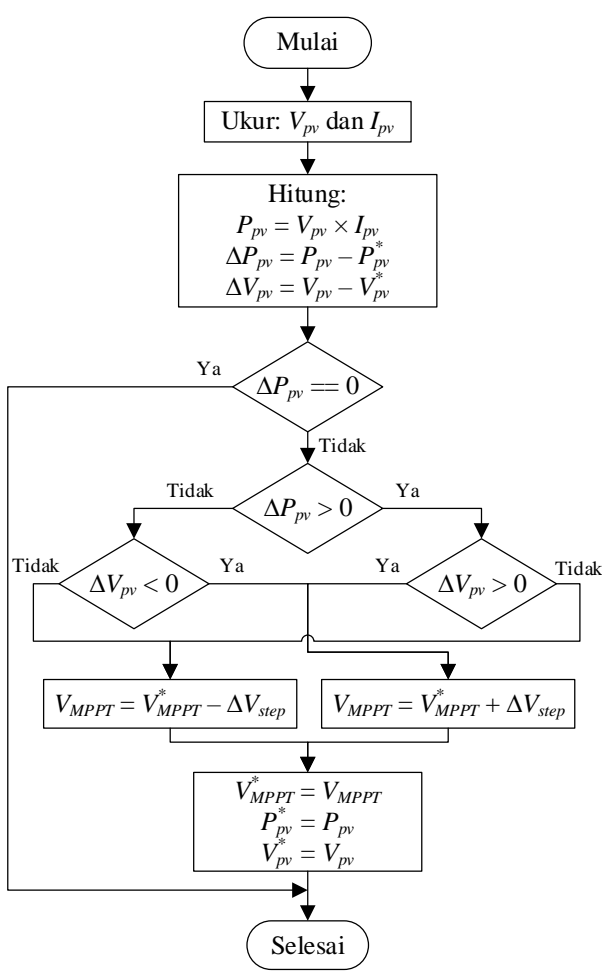

Gambar 3. Diagram alur algoritma $\mathrm{P} \& \mathrm{O}$

Konverter boost unidirectional yang terhubung ke PV dikendalikan oleh Maximum Power Point Tracking (MPPT). Algoritma MPPT yang digunakan pada penelitian ini adalah Perturb and Observe ( $\mathrm{P} \& \mathrm{O})$ dengan diagram alur pada Gambar 3. Metode $\mathrm{P} \& \mathrm{O}$ dipilih karena algoritmanya yang sederhana sehingga mudah diimplementasikan [17] - [20] dan memiliki perubahan variabel yang rendah saat pelacakan sedang berlangsung sehingga memiliki fluktuasi tegangan yang rendah.

\section{A. Skenario Mode-1: MPPT + Charging}

Selama skenario mode-1 beroperasi, tegangan referensi PV $v_{\text {pvRef }}$ hanya dihasilkan dari algoritma MPPT dan kedua loop kontrol lainnya $\left(\mathrm{PI}_{1}\right.$ dan $\left.\mathrm{PI}_{2}\right)$ dalam keadaan diam atau keluaran kontrol $\mathrm{PI}_{1}$ dan $\mathrm{PI}_{2}$ bernilai nol. Konverter PV unidirectional menginjeksi daya maksimum yang tersedia pada PV ke beban. Kontrol konverter baterai bidirectional mengendalikan aliran daya sistem dengan cara mengatur tegangan bus sesuai dengan setpoint (referensi) yang telah ditentukan. Ketika tegangan bus $v_{\text {bus }}$ lebih besar dari pada tegangan bus referensi $v_{\text {busRef, }}$, baterai dalam keadaan charging, seperti pada Gambar 4. Mode-1 beroperasi saat: 1) Daya keluaran konverter PV lebih besar dari pada daya beban, 2) $S o C$ baterai lebih kecil dari pada $S o C_{\max }$ yang telah ditentukan, dan 3) Arus pengisian baterai $i_{\text {bat }}$ untuk mengatur tegangan bus tidak melewati batas arus maksimal pengisian $i_{\text {bat-min }}$ yang telah ditentukan.

Ada beberapa metode untuk memperkirakan SoC baterai seperti yang telah diteliti dalam [21], [22]. Penelitian ini menggunakan metode yang paling umum digunakan yaitu dengan cara menghitung arus baterai untuk menentukan nilai perkiraan SoC dengan persamaan sebagai berikut:

$$
S o C=S o C_{0}+\frac{\eta}{C_{\text {bat }}} \int_{t_{0}}^{t} i_{\text {bat }}(\tau) d \tau
$$

di mana $S o C_{0}$ adalah nilai SoC awal (dalam persentase), $\eta$ adalah efisiensi charging dan discharging baterai, $C_{\text {bat }}$ adalah nominal kapasitas baterai (ampere-hour), dan $i_{\text {bat }}$ adalah arus baterai terukur.

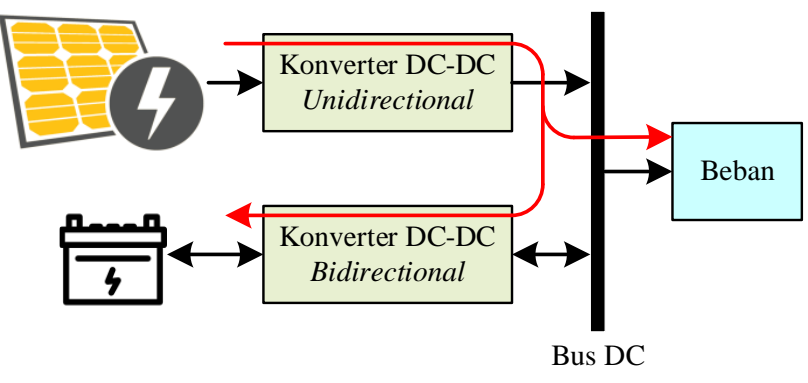

Gambar 4. Aliran daya saat mode-1 beroperasi

Ketika SoC baterai lebih ke kecil dari pada $S o C_{\max }$ yang telah ditentukan, sinyal error pada kontrol $\mathrm{PI}_{1}$ bernilai positif, yang mana keluaran kontrol $\mathrm{PI}_{1}$ bernilai nol karena batas saturasi tertinggi adalah nol. Oleh karena itu, kontrol loop SoC $\left(\mathrm{PI}_{1}\right)$ akan bernilai nol saat skenario operasi mode-1 berjalan. Begitu pula, selama arus pengisian baterai $i_{b a t}$ tidak melewati batas arus maksimal pengisian $i_{\text {bat-min }}$, error pada $\mathrm{PI}_{2}$ adalah positif, maka keluaran kontrol $\mathrm{PI}_{2}$ adalah nol. Arus baterai $i_{\text {bat }}$ bernilai positif saat discharging dan negatif saat charging, seperti diperlihatkan arah arus baterai $i_{\text {bat }}$ pada Gambar 2, maka nilai batas arus maksimal pengisian baterai $i_{\text {bat }}$ adalah negatif.

Proses pengisian baterai untuk mencapai $S o C_{\max }$ membutuhkan waktu yang cukup lama, begitu pula arus baterai $i_{\text {bat }}$ tidak selalu berada pada $i_{\text {bat-min }}$, sehingga keluaran kontrol integrator pada kontroler $\mathrm{PI}_{1}$ dan $\mathrm{PI}_{2}$ akan sangat besar. Oleh karena itu, mode anti-windup digunakan pada kontrol $\mathrm{PI}_{1}$ dan $\mathrm{PI}_{2}$ untuk membatasi keluaran integrator.

\section{B. Skenario Mode-2: MPPT}

Ketika daya keluaran PV cukup untuk menyuplai kebutuhan daya beban, mode ini akan beroperasi. Konverter PV unidirectional beroperasi pada Maximum Power Point (MPP) PV dan memasok seluruh daya PV ke beban sebagaimana dilihatkan pada Gambar 5. Sama halnya dengan skenario mode1, tegangan referensi PV $v_{\text {pvRef }}$ hanya dihasilkan dari algoritma MPPT dan kedua loop kontrol lainnya $\left(\mathrm{PI}_{1}\right.$ dan $\left.\mathrm{PI}_{2}\right)$ dalam keadaan diam atau keluaran kontrol $\mathrm{PI}_{1}$ dan $\mathrm{PI}_{2}$ bernilai nol. Pada mode ini, konverter baterai bidirectional tidak beroperasi.

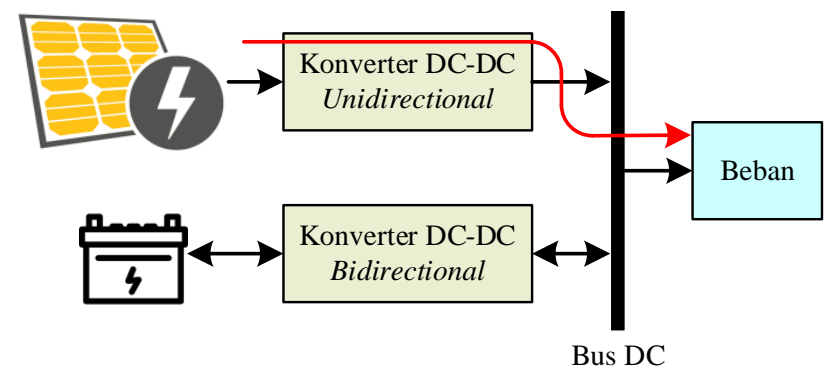

Gambar 5. Aliran daya saat mode-2 beroperasi

\section{Skenario Mode-3: MPPT + Discharging}

Skenario mode-3 beroperasi saat daya beban lebih besar dari pada daya yang dihasilkan oleh PV, sehingga membutuhkan daya tambahan dari baterai, seperti yang ditunjukkan pada Gambar 6. Kontroler konverter baterai bidirectional didesain sedemikian rupa sehingga daya PV dan baterai mampu menjaga tegangan bus $v_{\text {bus }}$, seperti yang ditunjukkan pada Gambar 2 (b). Sama halnya dengan skenario mode-1, tegangan referensi PV $v_{\text {pvRef }}$ hanya dihasilkan dari algoritma MPPT dan kedua loop kontrol lainnya $\left(\mathrm{PI}_{1}\right.$ dan $\left.\mathrm{PI}_{2}\right)$ dalam keadaan diam atau keluaran kontrol $\mathrm{PI}_{1}$ dan $\mathrm{PI}_{2}$ bernilai nol. 


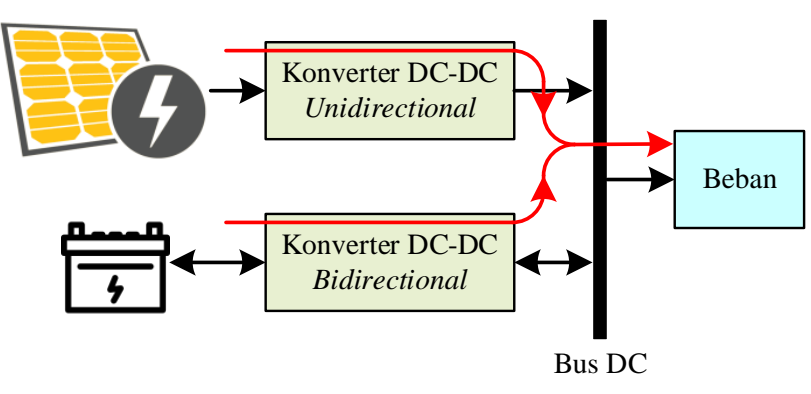

Gambar 6. Aliran daya saat mode-3 beroperasi

\section{Skenario Mode-4: Discharging}

Ketika iradiasi dari matahari tidak cukup untuk menghasilkan energi listrik, seluruh kebutuhan daya beban disuplai oleh baterai. Pengontrol konverter baterai bidirectional dirancang untuk memasok daya beban yang dibutuhkan dengan cara discharging baterai seperti ditunjukkan pada Gambar 7 .

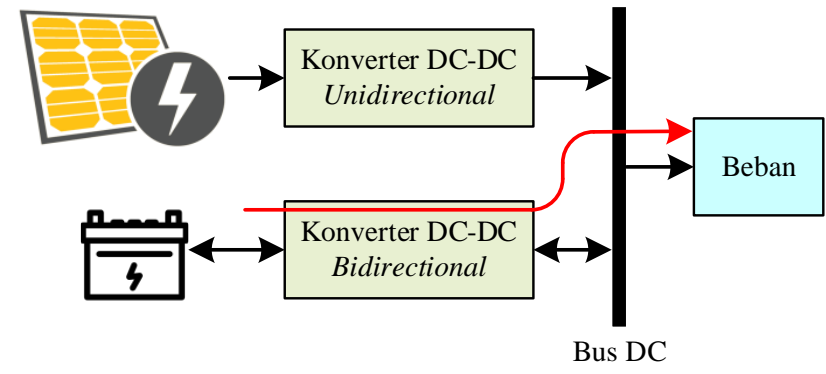

Gambar 7. Aliran daya saat mode-4 beroperasi

\section{E. Skenario Mode-5: Pengaturan SoC}

Skenario mode- 5 beroperasi ketika daya PV lebih besar dari pada daya beban dan baterai terisi (charging) hingga melebihi batas $S o C_{\max }$ yang telah ditentukan. Pada kondisi ini, nilai error masukan kontroler $\mathrm{PI}_{1}$ beserta keluaran $\mathrm{PI}_{1}$ mulai berubah menjadi negatif. Keluaran kontroler $\mathrm{PI}_{1}$ ini merepresentasikan tegangan yang akan ditambahkan ke tegangan referensi MPPT $v_{\text {MPPT }}$ untuk mendorong titik operasi PV menjauh dari titik daya maksimum (MPP) menuju area operasi sumber tegangan seperti terlihat pada kurva karakteristik PV Gambar 8. Oleh karena itu, loop ini akan terus mengurangi daya yang diekstraksi dari PV sampai arus baterai $i_{\text {bat }}$ turun ke nol dan SoC konstan di $S o C_{\max }$. Sistem akan terus beroperasi di mode ini selama daya PV mampu mencukupi kebutuhan beban. Dalam kondisi seperti ini, keluaran kontroler $\mathrm{PI}_{1}$ akan digunakan untuk menonaktifkan algoritma MPPT dan menjadikan $v_{\text {MPPT }}$ terakhir sebagai keluaran algoritma MPPT. Strategi menonaktifkan algoritma MPPT dapat dilakukan dengan memasukkan keluaran $\mathrm{PI}_{1}$ ke komparator yang menghasilkan logika 0 (nonaktif) ketika keluaran $\mathrm{PI}_{1}$ kurang dari nol dan menghasilkan logika 1 (aktif) ketika keluaran $\mathrm{PI}_{1}$ sama dengan nol. Ilustrasi aliran daya pada mode- 5 sama dengan aliran daya saat sistem beroperasi pada mode-2, hanya saja saat mode- 5 algoritma MPPT tidak aktif.

Dua macam gangguan dapat terjadi saat skenario mode ini beroperasi. Gangguan pertama, ketika beban $P_{\mathrm{L}}$ berkurang dan/atau daya PV $P_{\mathrm{pv}}$ meningkat karena iradiasi meningkat dan/atau suhu permukaan panel surya menurun. Konverter baterai bidirectional akan menyerap kelebihan daya pada bus DC untuk menjaga tegangan bus DC $v_{\text {bus }}$ tetap stabil/konstan. Sebagai akibatnya, loop kontrol SoC akan bereaksi pada gangguan tersebut dengan cara mengurangi daya PV sampai arus baterai $i_{\text {bat }}$ sama dengan nol dan SoC baterai kembali pada posisi $S o C_{\max }$.
Gangguan kedua terjadi ketika beban bertambah dan/atau daya PV berkurang. Pada kasus ini, baterai akan bereaksi untuk menyuplai defisit daya untuk menjaga tegangan bus DC. Oleh karena itu, error pada masukan kontroler $\mathrm{PI}_{1}$ bernilai positif dan, sebagai akibatnya, titik operasi PV mulai bergerak menuju MPP sehingga menyuplai lebih banyak daya ke bus DC sehingga arus baterai $i_{\text {bat }}$ berkurang sampai nol. Perlu digaris bawahi bahwa kontroler $\mathrm{PI}_{1}$ terus menerus mengatur SoC pada $S o C_{\max }$ selama daya keluaran PV lebih besar dari daya beban. Jika beban terus meningkat dan/atau daya PV terus berkurang, loop SoC akan terus menggerakkan titik operasi menuju MPP. Pada titik ini, PV sedang menyuplai daya semaksimal mungkin ke beban dan daya beban tambahan di luar batas akan disuplai oleh baterai seperti dalam mode-3. Mode- 6 beroperasi secara mandiri berperan menjaga keseimbangan daya dalam sistem tanpa ada syarat kondisi yang harus terpenuhi [4]. Selama skenario mode ini berlangsung, kontroler $\mathrm{PI}_{2}$ diasumsikan dalam keadaan diam (idle).

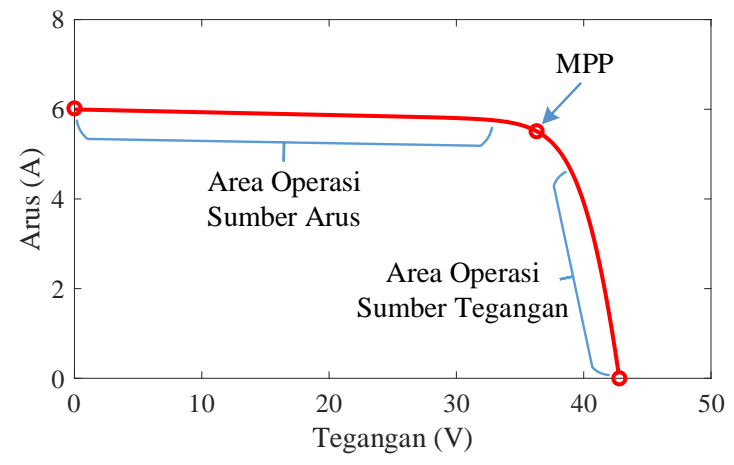

Gambar 8. Kurva karakteristik berdasarkan area operasi PV

\section{F. Skenario Mode-6: Pengaturan Arus Charging}

Sebagaimana yang telah dibahas sebelumnya, selama operasi mode-1, ketika daya PV lebih besar dari pada daya beban, baterai akan menyerap kelebihan daya tersebut dalam rangka untuk menjaga tegangan bus DC $v_{\text {bus. }}$ Bagaimanapun juga, arus pengisian (charging) baterai dibatasi oleh $i_{\text {bat-min }}$ yang telah ditentukan seperti yang ditunjukkan pada Gambar 2 (a) yang mana batasan maksimal arus pengisian baterai tergantung pada bahan kimia baterai, yaitu $\mathrm{C} / 5$ untuk baterai tipe Lead Acid, di mana $\mathrm{C}$ adalah nominal kapasitas baterai. Batasan arus maksimal pengisian baterai dapat diperkecil menjadi $\mathrm{C} / 10$ untuk memperpanjang life-time baterai, sebagai akibatnya adalah waktu pengisian baterai menjadi lebih lama [4].

Mode- 6 beroperasi saat daya yang dibangkitkan PV besar tapi daya beban kecil, sehingga arus pengisian baterai dapat meningkat melebihi batas arus maksimal pengisian. Kontroler $\mathrm{PI}_{2}$ pada Gambar 2 (a) akan mengendalikan arus charging sampai pada batas $i_{\text {bat-min. Ketika arus pengisian baterai }}$ meningkat sampai pada batas $i_{\text {bat-min, }}$, surplus daya PV tidak bisa terserap semua, sehingga mengakibatkan naiknya tegangan bus DC $v_{\text {bus. }}$ Oleh karena itu, daya PV perlu dikurangi untuk menjaga keseimbangan daya pada sistem. Ketika $i_{\text {bat }}$ melewati batas $i_{\text {bat-min }}$, nilai error masukan dan keluaran kontroler $\mathrm{PI}_{2}$ akan bernilai negatif, sehingga loop $\mathrm{PI}_{2}$ mulai meningkatkan tegangan referensi PV $v_{\text {pvRef }}$ menjauhi MPP menuju area operasi sumber tegangan karakteristik kurva I-V pada Gambar 8 , proses tersebut sama halnya saat loop $\mathrm{PI}_{1}$ beroperasi. Sekali lagi, algoritma MPPT akan dinonaktifkan dan keluaran MPPT bernilai $v_{\text {MPPT }}$ terakhir sebelum dinonaktifkan. 
Gangguan berupa peningkatan daya PV dan/atau penurunan daya beban saat mode- 6 sedang beroperasi akan menyebabkan $v_{\text {bus }}$ meningkat, maka konverter baterai akan merespons dengan menyerap surplus daya PV, sehingga arus charging bertambah dan melebihi batas maksimal. Selanjutnya, kontroler $\mathrm{PI}_{2}$ mendorong $v_{\text {pvRef }}$ untuk lebih menjauh lagi dari MPP agar daya yang terekstrak oleh PV semakin berkurang, sehingga arus charging dapat dibatasi. Begitu juga sebaliknya, loop $\mathrm{PI}_{2}$ akan menarik $v_{\text {pvRef }}$ untuk mendekati MPP saat daya PV menurun dan/atau daya beban meningkat.

\section{HASIL DAN PEMBAHASAN}

Skema strategi dan kontrol yang diusulkan telah diverifikasi menggunakan perangkat lunak MATLAB/Simulink dengan menggunakan tipe solver Tustin/Backward Euler (TBE) pada frekuensi sampling sebesar $200 \mathrm{kHz}$. Skema strategi dan kontrol yang diusulkan telah diuji dengan enam skenario mode operasi yang berbeda-beda. Data teknis parameter sistem yang diusulkan disajikan pada Tabel I.

\section{A. Operasi Mode-1 sampai Mode-4}

Performa sistem saat beroperasi pada mode normal (mode 1-4) ditunjukkan pada Gambar 9. PV menerima iradiasi sebesar $1 \mathrm{~kW} / \mathrm{m}^{2}$ mulai dari 0 sampai 15 detik, kemudian turun perlahan sampai tidak menerima iradiasi rama sekali pada detik ke-16. Algoritma MPPT mulai melacak MPP mulai dari $V_{O C}$ hingga berosilasi di sekitar $V_{M P}$. Waktu yang dibutuhkan algoritma P\&O untuk menemukan MPP sangat tergantung pada step-size $\left(\Delta V_{\text {step }}\right)$ dan sampling waktu (time sampling) yang ditentukan,
TABEL I. PARAMETER SISTEM

\begin{tabular}{lcc}
\hline \hline \multicolumn{1}{c}{ Deskripsi } & Parameter & Nilai \\
\hline Daya maksimum PV & $P_{\max }$ & $200 \mathrm{~W}$ \\
Tegangan open-circuit PV & $V_{O C}$ & $42,8 \mathrm{~V}$ \\
Arus short-circuit PV & $I_{S C}$ & $6,02 \mathrm{~A}$ \\
Tegangan max-power PV & $V_{M P}$ & $36,3 \mathrm{~V}$ \\
Arus max-power PV & $I_{M P}$ & $5,51 \mathrm{~A}$ \\
Setpoint tegangan bus DC & $V_{b u s}$ & $48 \mathrm{~V}$ \\
Nominal tegangan baterai & $V_{b a t}$ & $24 \mathrm{~V}$ \\
Kapasitas baterai & $C_{b a t}$ & $18 \mathrm{Ah}$ \\
Induktor konverter PV & $L_{p v}$ & $560 \mathrm{uH}$ \\
Induktor konverter baterai & $L_{b a t}$ & $2 \mathrm{mH}$ \\
Kapasitor PV & $C_{p v}$ & $670 \mathrm{uF}$ \\
Kapasitor baterai & $C_{b a t}$ & $2 \mathrm{mF}$ \\
Kapasitor keluaran konverter & $C_{b u s l}, C_{b u s 2}$ & $1 \mathrm{mF}$ \\
Frekuensi switching & $f_{s w}$ & $10 \mathrm{kHz}$ \\
\hline
\end{tabular}

step-size dan time-sampling pada penelitian ini ditentukan sebesar $0,5 \mathrm{~V}$ dan $0,1 \mathrm{~s}$, sehingga MPPT dapat menemukan MPP pada detik ke-1,4. Daya rata-rata yang mampu dilacak oleh P\&O adalah 199,9 W.

Awal mula saat proses pelacakan MPP berlangsung, konverter PV tidak dapat menyuplai keseluruhan daya yang dibutuhkan beban sehingga sebagian kebutuhan daya beban ditanggung baterai. Ketika proses pelacakan MPP berlangsung, daya PV yang mampu diserap oleh konverter semakin lama akan semakin meningkat hingga melebihi daya beban, maka kelebihan daya beban akan diserap oleh baterai (mode-1). Mode- 1 beroperasi mulai dari 0,6 s sampai $5 \mathrm{~s}$, dengan beban bus mulai dari awal sistem berjalan sampai pada $5 \mathrm{~s}$ sebesar 20

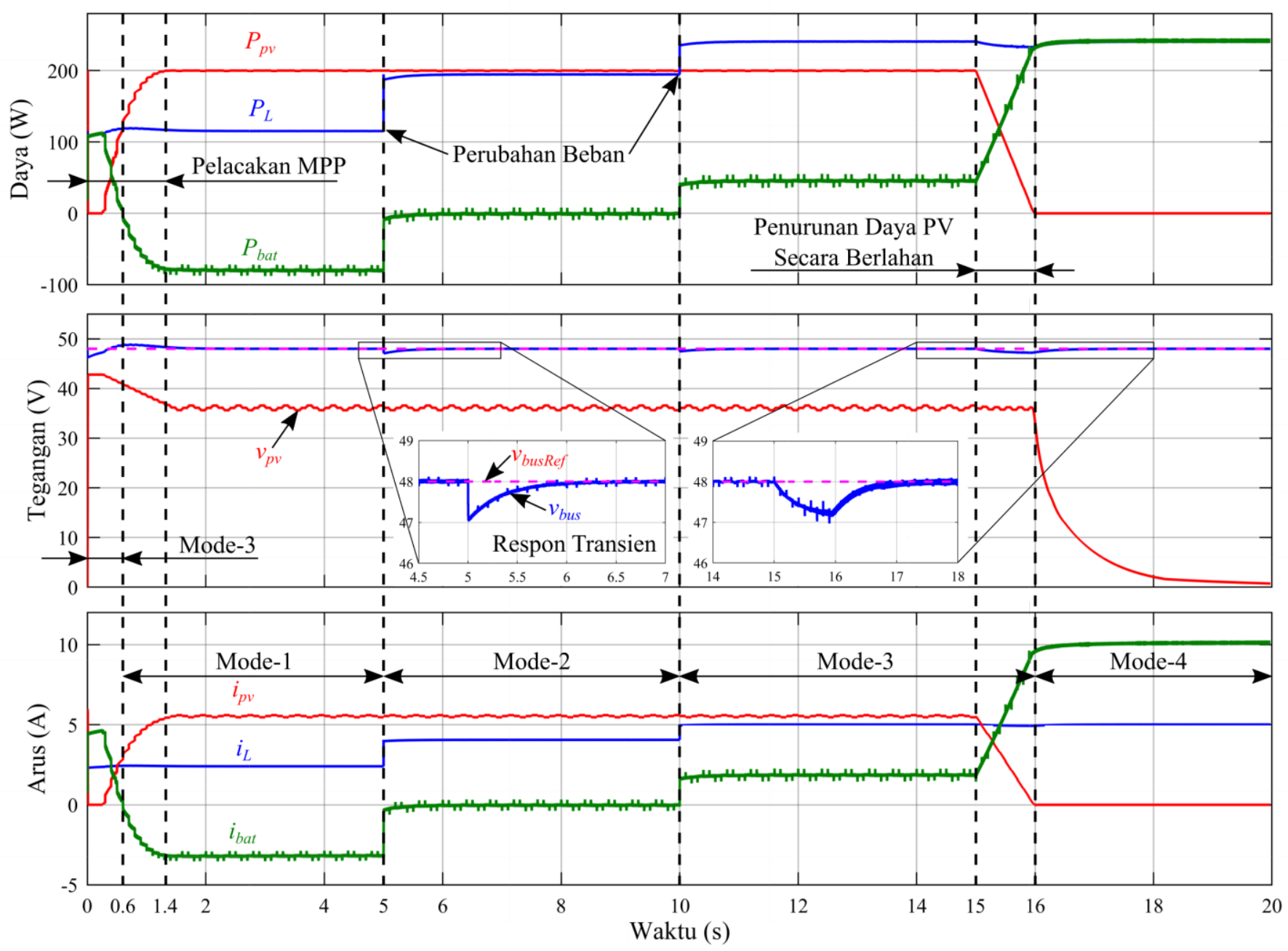

Gambar 9. Performa sistem saat beroperasi pada mode-1 sampai mode-4 
Ohm. Daya yang diserap beban dan baterai (charging) setelah steady-state saat mode-1 beroperasi adalah sebesar 115,3 W dan $-79,82 \mathrm{~W}$ dengan arus baterai $i_{\text {bat }}$ sebesar -3,19 A. Sinyal negatif pada arus dan daya baterai menunjukkan proses charging baterai, begitu pula sebaliknya menunjukkan proses discharging baterai. Mode-2 terjadi pada detik 5-10, detik ke-5 beban berubah seketika dari $20 \Omega$ menjadi $11,84 \Omega$, maka kebutuhan daya beban semakin besar dan sama dengan daya yang dikeluarkan oleh konverter PV yaitu 194,6 W sehingga baterai dalam keadaan diam atau arus baterai $i_{\text {bat }}$ sama dengan nol. Ketika mode-2 beroperasi, algoritma MPPT masih berjalan dan algoritma MPPT mampu menemukan daya terbaiknya sebesar 199,9 W. Selisih daya antara masukan dan keluaran konverter PV merupakan hal yang wajar, karena ada rugi-rugi (losses) daya pada konverter.

Detik ke-10 beban berubah lagi dari 11,84 $\Omega$ menjadi 9,57 $\Omega$ seketika. Oleh karena itu, muncul sinyal transien pada kurva tegangan bus $v_{\text {bus. }}$ Sinyal transien akan selalu muncul saat ada fluktuasi beban mendadak, seperti yang terlihat pada pembesaran sinyal respon transien Gambar 9. Ketika daya beban melebihi daya konverter PV, konverter baterai akan menyuplai kekurangan daya tersebut dalam rangka untuk mengendalikan tegangan bus $v_{\text {bus }}$ sesuai dengan referensi (setpoint). Daya baterai yang disuntikkan ke beban pada mode3 setelah steady-state adalah sebesar 45,48 W, sedangkan daya yang diserap beban sebesar 240,7 W.

Iradiasi yang diterima PV berkurang secara perlahan sampai tidak ada lagi iradiasi yang diterima mulai dari detik 15 sampai 16, begitu juga daya keluaran PV. Selama proses berkurangnya daya PV secara perlahan, konverter baterai menyuplai defisit daya pada beban secara perlahan pula. Mode-4 beroperasi saat PV tidak dapat menghasilkan energi lagi, maka total kebutuhan beban akan disuplai baterai. Daya baterai dan beban saat mode4 adalah $241,9 \mathrm{~W}$ dan $240,7 \mathrm{~W}$.

Hasil pengujian pada Gambar 9 saat mode 1-4 menunjukkan bahwa tegangan bus $v_{\text {bus }}$ selalu pada posisi tegangan setpoint $v_{\text {busRef }}$ meski beban dan iradiasi matahari berubah-ubah dan algoritma MPPT selalu aktif. Tegangan bus tetap terjaga pada tegangan referensi dikarenakan konverter DC-DC bidirectional mampu mengendalikan aliran daya pada sistem. Baterai melalui konverter DC-DC bidirectional akan menyerap kelebihan daya yang dihasilkan PV saat tegangan bus $v_{\text {bus }}$ lebih besar dari pada tegangan referensi $v_{\text {busRef. Masukan }}$ dan keluaran kontrol loop $\mathrm{PI}_{5}$ akan bernilai negatif saat tegangan bus lebih besar dari pada tegangan referensi, maka konverter DC-DC bidirectional akan beroperasi pada mode buck (step-down) atau charging, sehingga tegangan bus tetap terkendali, begitu juga sebaliknya saat tegangan bus $v_{\text {bus }}$ lebih kecil dari pada tegangan referensi $v_{\text {busRef, baterai akan memasok }}$ daya ke beban. Temuan yang diperoleh pada penelitian ini saat mode 1-4 beroperasi kurang lebih sama dengan studi yang telah dilakukan sebelumnya pada [4], [8], [9], [14], [15].

\section{B. Pengaturan SoC (Mode-5)}

Nilai awal $S o C_{0}$ baterai sebesar $89,99 \%$ saat sistem mulai berjalan pada pengujian kali ini, sehingga mode-5 (loop $\mathrm{PI}_{1}$ ) belum beroperasi mulai dari awal. Gambar 10 menunjukkan kontrol loop $\mathrm{PI}_{1}$ bekerja untuk mengatur tegangan masukan PV menjauhi $V_{\text {MPP }}$ ketika $S o C$ baterai mencapai $S o C_{\max }$ Peningkatan $v_{\mathrm{pv}}$ dipacu ketika SoC melewati batas $S o C_{\text {max }}$ pada detik ke-3.4, saat itu juga algoritma MPPT tidak aktif. Referensi tegangan keluaran PV kemudian meningkat dari ratarata $36,13 \mathrm{~V}$ menjadi $41,08 \mathrm{~V}$, perpindahan titik operasi menjauh dari MPP berakibat turunnya daya keluaran PV dari 159,3 W menjadi 78,67 W. Penurunan daya PV tersebut untuk memberhentikan proses charging baterai karena sudah melebihi dari batas $S o C_{\max }$.

Ketika MPP PV turun akibat berkurangnya iradiasi dari $159,5 \mathrm{~W}$ menjadi $118,8 \mathrm{~W}$ pada detik ke-8, konverter baterai merespons dengan cepat untuk menyuplai defisit daya sesaat akibat turunnya daya PV. Semenjak baterai menyuplai defisit daya ke beban, SoC baterai akan berkurang sehingga error pada masukan kontroler $\mathrm{PI}_{1}$ akan bernilai positif. Oleh karena itu, tegangan $\mathrm{PV}$ akan didorong oleh kontroler $\mathrm{PI}_{1}$ untuk mendekati MPP dari 41,08 V menjadi 40,04 V, sehingga daya sistem kembali seimbang dan $\mathrm{SoC}$ baterai kembali ke $S o C_{\max }$. Performa sistem pada mode-5 diuji saat MPP berubah pada detik ke-12, di mana MPP meningkat dari 118,8 W menjadi $139,1 \mathrm{~W}$. Konverter baterai merespons dengan cepat untuk menyerap surplus daya $\mathrm{PV}$, dan kemudian loop $\mathrm{PI}_{1}$ menggeser titik operasi PV kembali menjauhi MPP untuk menyeimbangkan aliran daya sistem dan SoC baterai kembali ke $S O C_{\max }$. Unjuk kinerja kontroler $\mathrm{PI}_{1}$ juga diuji saat resistansi beban berubah dari $30 \Omega$ menjadi $20 \Omega$ pada detik ke-16, di mana arus beban meningkat dari 1,6 A menjadi 2,4 A. Konverter baterai merespons dengan cepat untuk memenuhi beban, dan kemudian loop $\mathrm{PI}_{1}$ menggeser titik operasi $\mathrm{PV}$ mendekati MPP untuk memaksimalkan masukan iradiasi matahari.

Hasil pengujian pada Gambar 10 saat daya PV melebihi daya beban dan baterai pada kondisi penuh (mode 5) menunjukkan bahwa sistem kontrol loop $\mathrm{PI}_{1}$ yang diusulkan mampu menjaga SoC baterai pada batas $S o C_{\max }$ dan mengendalikan tegangan bus $v_{\text {bus }}$ selalu pada posisi tegangan setpoint $v_{\text {busRef }}$ meski beban dan iradiasi matahari berubah-ubah. Masukan dan keluaran kontrol loop $\mathrm{PI}_{1}$ akan bernilai negatif saat SoC baterai melebihi $S o C_{\max }$, sehingga kontrol loop $\mathrm{PI}_{1}$ akan menonaktifkan algoritma MPPT dan mendorong tegangan PV menjauhi MPP sampai daya keluaran konverter DC-DC unidirectional sama dengan daya beban. Temuan yang diperoleh pada penelitian ini saat mode 5 beroperasi kurang lebih sama dengan studi yang telah dilakukan sebelumnya pada [4], [8], [9], [11].

\section{Pengaturan Arus Charging (Mode 6)}

Ketika daya beban sangat rendah, daya surplus PV dapat diserap baterai melebihi batas maksimal arus charging baterai $i_{\text {bat-min. }}$ Batas maksimal arus charging baterai $i_{\text {bat-min }}$ pada penelitian ini adalah -3,6 A, tanda negatif menunjukkan arus charging, sedangkan tanda positif untuk arus discharging. Skenario ini dapat dilihat pada Gambar 11. Awal sistem berjalan, arus charging setelah steady-state $\left(i_{\text {bat }}=-2,9 \mathrm{~A}\right)$ tidak sampai melewati batas maksimal. Daya PV meningkat seketika pada detik ke-4 dan beban tidak berubah, sehingga arus charging melebihi batas. Ketika arus charging melebihi batas, error masukkan dan keluaran loop $\mathrm{PI}_{2}$ akan bernilai negatif, maka algoritma MPPT tidak aktif dan loop $\mathrm{PI}_{2}$ mendorong tegangan referensi PV akan menjauh dari MPP dari 36,13 V menjadi 39,26 V, sehingga arus charging berada pada batas maksimal. Ketika mode- 6 beroperasi, performa sistem diuji dengan gangguan berupa fluktuasi MPP PV. MPP PV menurun dari $200 \mathrm{~W}$ menjadi $179,7 \mathrm{~W}$ pada detik ke-8, sehingga loop $\mathrm{PI}_{2}$ memindahkan tegangan PV $v_{\mathrm{pv}}$ untuk mendekat MPP dari 39,26 V menjadi 37,51 V. Sekali lagi, kontrol yang diusulkan mampu menjaga arus charging agar tidak melebihi batas maksimalnya. 


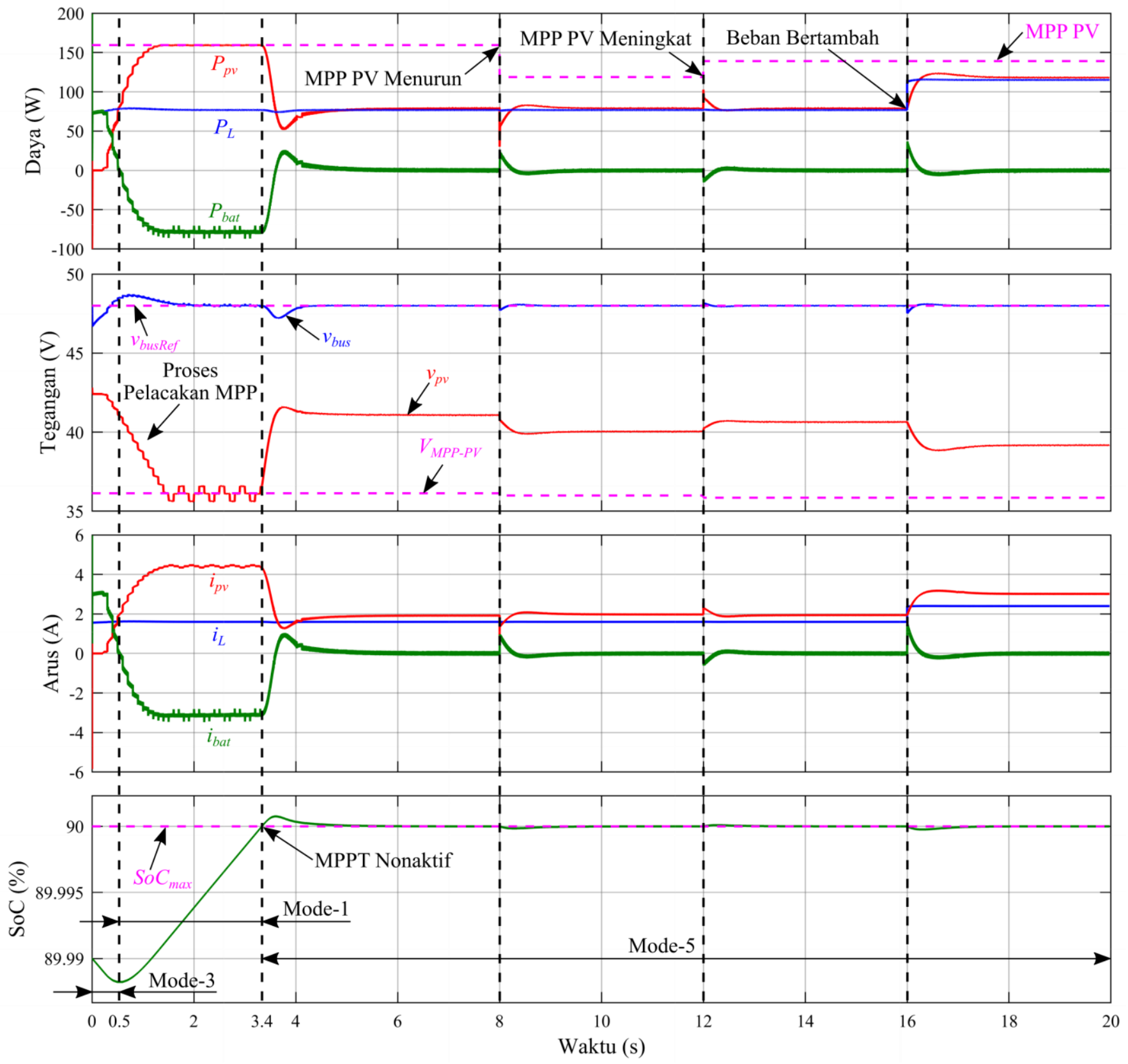

Gambar 10. Performa sistem saat pengaturan SoC beroperasi

Penurunan beban terjadi pada detik ke-12 yang mengakibatkan semakin tingginya surplus daya PV, maka loop $\mathrm{PI}_{2}$ menambahkan tegangan $\mathrm{PV} v_{\mathrm{pv}}$ dari $37,51 \mathrm{~V}$ menjadi 39,39 $\mathrm{V}$, sehingga arus charging tetap di posisi pada batasan maksimal. Ketika surplus daya PV tidak terlalu besar, sistem akan kembali beroperasi pada mode-1 dan algoritma MPPT akan kembali aktif untuk melacak daya maksimum PV, seperti yang ditunjukkan pada Gambar 11 detik ke-16. Meskipun sistem menerima berbagai macam gangguan saat mode-6 beroperasi, skema kontrol yang diusulkan tetap dapat mengendalikan tegangan bus DC $v_{\text {bus }}$ pada posisi tegangan bus referensi $v_{\text {busRef. }}$

Hasil pengujian pada Gambar 11 saat daya PV melebihi daya beban dan arus charging baterai melebihi batas maksimal (mode 6) menunjukkan bahwa sistem kontrol loop $\mathrm{PI}_{2}$ yang diusulkan mampu menjaga arus charging baterai $i_{\text {bat }}$ pada batas arus charging maksimal $i_{\text {bat-min }}$ dan mengendalikan tegangan bus $v_{\text {bus }}$ selalu pada posisi tegangan setpoint $v_{\text {busRef }}$ tanpa menimbulkan deviasi tegangan pada sisi bus meski beban dan iradiasi matahari berubah-ubah. Masukan dan keluaran kontrol loop $\mathrm{PI}_{2}$ akan bernilai negatif saat arus charging baterai $i_{\text {bat }}$ melebihi $i_{\text {bat-min }}$, sehingga kontrol loop $\mathrm{PI}_{2}$ akan menonaktifkan algoritma MPPT dan mendorong tegangan PV menjauhi MPP sampai daya keluaran konverter DC-DC unidirectional sama dengan daya beban. Temuan yang diperoleh pada penelitian ini saat mode 6 beroperasi tidak ditemukan di studi sebelumnya pada [8], [9], [11]. Hasil pengujian mode 6 pada penelitian ini memiliki perbedaan dengan hasil penelitian yang diusulkan pada [4]. Perbedaan tersebut disebabkan oleh masukan kontrol $\mathrm{PI}_{2}$ yang berbeda. Referensi [4] menggunakan masukan $\mathrm{PI}_{2}$ berupa selisih antara $v_{\text {busRef }}+\Delta V$ dengan $v_{\text {bus }}$, di mana $\Delta V$ adalah maksimum deviasi tegangan yaitu $5 \%$ dari $\nu_{\text {busRef, }}$ sehingga hasil studi [4] menimbulkan deviasi pada tegangan bus $v_{\text {bus }}$ sebesar 5\%. Sedangkan pada penelitian ini mengusulkan desain kontrol masukan $\mathrm{PI}_{2}$ berupa selisih antara $i_{\text {bat }}$ dengan $i_{\text {bat-min, }}$ sehingga hasil penelitian ini saat mode 6 tidak terdapat deviasi tegangan pada $v_{\text {bus. }}$. 


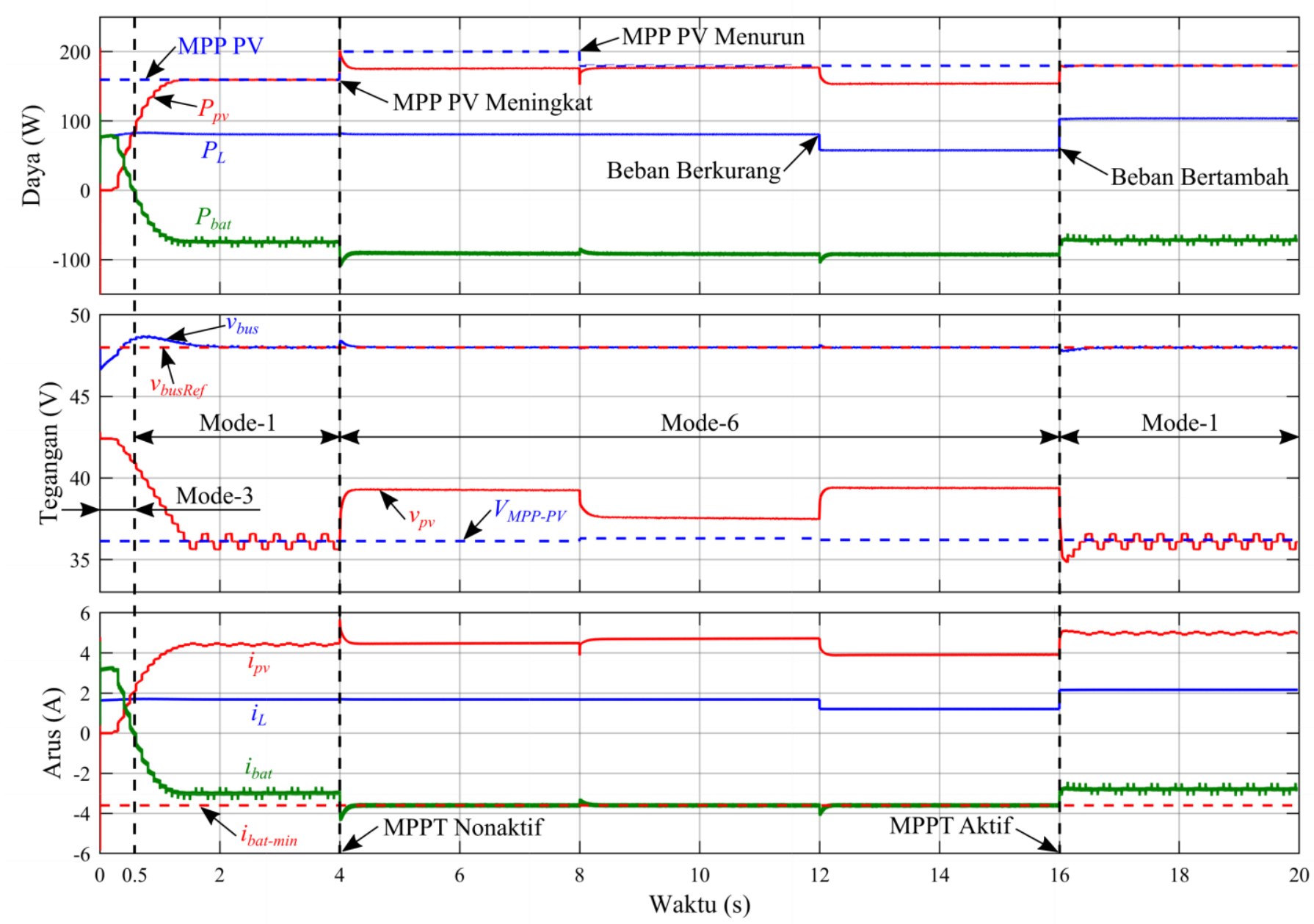

Gambar 11. Performa sistem saat pengaturan arus charging

\section{IV.PENUTUP}

Strategi kontrol multi-loop untuk mengendalikan arus pengisian baterai pada sistem hibrid PV standalone telah dibuat dan diuji. Strategi ini mampu mengontrol konverter daya PV dan konverter daya baterai bidirectional dengan batasan pengoperasian arus charging dan SoC baterai tanpa menimbulkan deviasi pada tegangan bus. Berdasarkan SoC baterai, daya maksimum PV, dan daya beban, operasi sistem telah dikategorikan ke dalam enam skenario operasi untuk mengelola aliran daya sistem dengan lancar dan halus dengan tetap menjaga batas arus charging dan SoC baterai. Hasil simulasi dari sistem $200 \mathrm{~W}$ telah disajikan dan memvalidasi strategi pengendalian yang diusulkan dalam kondisi beban dan iradiasi yang berubah-ubah. Saran untuk penelitian selanjutnya adalah menambahkan inverter DC-AC pada sistem PV-baterai, sehingga sistem dapat memasok beban DC dan AC.

\section{REFERENSI}

[1] M. R. Mojallizadeh and M. A. Badamchizadeh, "Adaptive PassivityBased Control of a Photovoltaic/Battery Hybrid Power Source via Algebraic Parameter Identification," IEEE J. Photovoltaics, vol. 6, no. 2, pp. 532-539, 2016, doi: 10.1109/JPHOTOV.2016.2514715.

[2] Z. Yi, W. Dong, and A. H. Etemadi, "A unified control and power management scheme for PV-Battery-based hybrid microgrids for both grid-connected and islanded modes," IEEE Trans. Smart Grid, vol. 9, no. 6, pp. 5975-5985, 2018, doi: 10.1109/TSG.2017.2700332.

[3] J. Hong, J. Yin, Y. Liu, J. Peng, and H. Jiang, "Energy Management and Control Strategy of Photovoltaic/Battery Hybrid Distributed Power Generation Systems with an Integrated Three-Port Power Converter," IEEE Access, vol. 7, pp. 82838-82847, 2019, doi: 10.1109/ACCESS.2019.2923458

[4] H. Mahmood, D. Michaelson, and J. Jiang, "Control strategy for a standalone PV/battery hybrid system," IECON Proc. (Industrial Electron. Conf., pp. 3412-3418, 2012, doi: 10.1109/IECON.2012.6389351.

[5] M. Alramlawi and P. Li, "Design optimization of a residential pv-battery microgrid with a detailed battery lifetime estimation model," IEEE Trans. Ind. Appl., vol. 56, no. 2, pp. 2020-2030, 2020, doi: 10.1109/TIA.2020.2965894.

[6] S. Armstrong, M. E. Glavin, and W. G. Hurley, "Comparison of battery charging algorithms for stand alone photovoltaic systems," PESC Rec. IEEE Аnnu. Power Electron. Spec. Conf., pp. 1469-1475, 2008, doi 10.1109/PESC.2008.4592143.

[7] S. Dhundhara, Y. P. Verma, and A. Williams, "Techno-economic analysis of the lithium-ion and lead-acid battery in microgrid systems," Energy Convers. Manag., vol. 177, pp. 122-142, 2018, doi https://doi.org/10.1016/j.enconman.2018.09.030.

[8] A. Mirzaei, M. Forooghi, A. A. Ghadimi, A. H. Abolmasoumi, and M. R. Riahi, "Design and construction of a charge controller for stand-alone $\mathrm{PV} /$ battery hybrid system by using a new control strategy and power management," Sol. Energy, vol. 149, pp. 132-144, 2017, doi 10.1016/j.solener.2017.03.046

[9] S. Wen, S. Wang, G. Liu, and R. Liu, "Energy management and coordinated control strategy of PV/HESS AC microgrid during islanded operation," IEEE Access, vol. 7, no. c, pp. 4432-4441, 2019, doi: 10.1109/ACCESS.2018.2887114.

[10] S. Marhraoui, A. Abbou, Z. Cabrane, S. E. Rhaili, and N. El Hichami, "Fuzzy logic-integral backstepping control for PV grid-connected system with energy storage management," Int. J. Intell. Eng. Syst., vol. 13, no. 3, pp. 359-372, 2020, doi: 10.22266/IJIES2020.0630.33.

[11] Y. Yang, Y. Qin, S. C. Tan, and S. Y. R. Hui, "Efficient Improvement of Photovoltaic-Battery Systems in Standalone DC Microgrids Using a Local Hierarchical Control for the Battery System," IEEE Trans. Power Electron., vol. 34, no. 11, pp. 10796-10807, 2019, doi 10.1109/TPEL.2019.2900147.

[12] H. Mahmood, D. Michaelson, and J. Jiang, "A power management strategy for PV/battery hybrid systems in Islanded microgrids," IEEE J. Emerg. Sel. Top. Power Electron., vol. 2, no. 4, pp. 870-882, 2014, doi 10.1109/JESTPE.2014.2334051. 
[13] H. Mahmood, D. Michaelson, and J. Jiang, "Decentralized Power Management of a PV/Battery Hybrid Unit in a Droop-Controlled Islanded Microgrid," IEEE Trans. Power Electron., vol. 30, no. 12, pp. 7215-7229, 2015, doi: 10.1109/TPEL.2015.2394351.

[14] S. Jain, S. Dhara, and V. Agarwal, "A Voltage-Zone Based Power Management Scheme with Seamless Power Transfer between PVBattery for OFF-Grid Stand-Alone System," IEEE Trans. Ind. Appl., vol. 57, no. 1, pp. 754-763, 2021, doi: 10.1109/TIA.2020.3031265.

[15] D. Bhule, S. Jain, and S. Ghosh, "Power management control strategy for PV-Battery standalone system," PIICON 2020 - 9th IEEE Power India Int. Conf., pp. 0-5, 2020, doi: 10.1109/PIICON49524.2020.9112970.

[16] R. Das, H. Rashid, and I. U. Ahmed, "A comparative analysis of PI and PID controlled bidirectional DC-DC converter with conventional bidirectional DC-DC converter," 3rd Int. Conf. Electr. Inf. Commun. Technol. EICT 2017, vol. 2018-January, no. December, pp. 1-6, 2018 doi: 10.1109/EICT.2017.8275149.

[17] Machmud Effendy, N. A. Mardiyah, and K. Hidayat, "Implementasi Maximum Power Point Tracking pada Photovoltaic Berbasis P\&OFuzzy," Jnteti, vol. 6, no. 1, pp. 2-7, 2017.

[18] D. Juniyanto, T. Andrasto, and S. Suryono, "Optimalisasi Stand-Alone
Photovoltaic System dengan Implementasi Algoritma P\&O-Fuzzy MPPT," J. Tek. Elektro, vol. 10, no. 1, pp. 1-10, 2018, doi 10.15294/jte.v10i1.14108.

[19] K. Hidayat, R. N. Hasanah, and H. Suyono, "Hybrid improved differential evolution and spline-based Jaya for photovoltaic MPPT technique," Int. Conf. Electr. Eng. Comput. Sci. Informatics, pp. 344 351, 2019, doi: 10.23919/EECSI48112.2019.8976977.

[20] S. A. Mohamed and M. Abd El Sattar, "A comparative study of P\&O and INC maximum power point tracking techniques for grid-connected PV systems," SN Appl. Sci., vol. 1, no. 2, pp. 1-13, 2019, doi: 10.1007/s42452-018-0134-4

[21] M. Coleman, C. K. Lee, C. Zhu, and W. G. Hurley, "State-of-charge determination from EMF voltage estimation: Using impedance, terminal voltage, and current for lead-acid and lithium-ion batteries," IEEE Trans. Ind. Electron., vol. 54, no. 5, pp. 2550-2557, 2007, doi: 10.1109/TIE.2007.899926.

[22] P. Thounthong, S. Raël, and B. Davat, "Control algorithm of fuel cell and batteries for distributed generation system," IEEE Trans. Energy Convers., vol. 23, no. 1, pp. 148-155, 2008, doi: 10.1109/TEC.2006.888028. 